1 Comparisons among the five ground-motion models developed using RESORCE for the 2 prediction of response spectral accelerations due to earthquakes in Europe and the Middle East

3 John Douglas ${ }^{1}$, Sinan Akkar ${ }^{2}$, Gabriele Ameri ${ }^{3}$, Pierre-Yves Bard ${ }^{4}$, Dino Bindi ${ }^{5}$, Julian J. Bommer ${ }^{6}$, 4 Sanjay Singh Bora ${ }^{7}$, Fabrice Cotton ${ }^{4}$, Boumédiène Derras ${ }^{4}$, Marcel Hermkes ${ }^{7}$, Nicolas Martin Kuehn ${ }^{7}$, 5 Lucia Luzi ${ }^{8}$, Marco Massa ${ }^{8}$, Francesca Pacor ${ }^{8}$, Carsten Riggelsen $^{7}$, M. Abdullah Sandıkkaya ${ }^{2}$, $6 \quad$ Frank Scherbaum ${ }^{7}$, Peter J. Stafford ${ }^{6}$, Paola Traversa ${ }^{9}$

\title{
Abstract
}

This article presents comparisons among the five ground-motion models described in other articles within this special issue, in terms of data selection criteria, characteristics of the models and predicted peak ground and response spectral accelerations. Comparisons are also made with predictions from the Next Generation Attenuation (NGA) models to which the models presented here have similarities (e.g. a common master database has been used) but also differences (e.g. some models in this issue are nonparametric). As a result of the differing data selection criteria and derivation techniques the predicted median ground motions show considerable differences (up to a factor of two for certain scenarios), particularly for magnitudes and distances close to or beyond the range of the available observations. The predicted influence of style-of-faulting shows much variation among models whereas site amplification factors are more similar, with peak amplification at around 1s. These differences are greater than those among predictions from the NGA models. The models for aleatory variability (sigma), however, are similar and suggest that ground-motion variability from this region is slightly higher than that predicted by the NGA models, based primarily on data from California and Taiwan.

Keywords: strong-motion data; ground-motion models; ground-motion prediction equations; style of faulting; site amplification; aleatory variability; epistemic uncertainty; Europe; Middle East.

\footnotetext{
${ }^{1}$ BRGM, Orléans, France

${ }^{2}$ Middle East Technical University, Ankara, Turkey

${ }^{3}$ FUGRO-Geoter, Auriol, France.

${ }^{4}$ ISTerre, Université Joseph Fourier, CNRS, Grenoble, France

${ }^{5}$ GFZ, Potsdam, Germany

${ }^{6}$ Imperial College London, United Kingdom

${ }^{7}$ Inst. Erd- und Umweltwissesnschaften, Universitaet Potsdam, Germany

${ }^{8}$ INGV, Milan, Italy

${ }^{9}$ EDF, Aix en Provence, France
} 
The collection of five ground-motion models presented in other articles in this special issue has similarities to the five sets of ground-motion prediction equations (GMPEs) derived during the Next Generation Attenuation (NGA) project (Power et al., 2008) and described in a special issue of Earthquake Spectra in 2008. Firstly, both sets of models were derived for state-of-the-art seismic hazard assessments for shallow active crustal seismicity in specific geographical regions: western North America (specifically California) for NGA, and Europe and the Middle East here. In passing it may be noted, however, that the NGA models have been shown to be applicable to Europe and the Middle East (Stafford et al., 2008). Secondly, all five GMPEs presented here were derived based on records chosen from a common strong-motion database (RESORCE, see Akkar et al., 2013c), whose compilation has similarities to the procedure followed when developing the NGA database (Chiou et al., 2008). Thirdly, careful data selections were made by each of the GMPE developers and state-ofthe-art derivation techniques were followed. Lastly, the collection of GMPEs produced seeks to acknowledge the still considerable epistemic uncertainty present in the assessment of earthquake shaking (e.g. Douglas, 2010). For the application of the NGA models within the USGS national hazard calculations additional branches were added to the logic-tree in certain magnitude-distance bins to capture epistemic uncertainty beyond that represented by these models (Petersen et al., 2008).

On the other hand, the collection presents significant differences with respect to the NGA models. Firstly, unlike the NGA models, which were all derived using regression analysis, generally the random-effects approach (e.g. Abrahamson and Youngs, 1992), (although with some coefficients fixed a priori based on physical arguments), here only two models were derived in this way (Akkar et al., 2013a, b; Bindi et al., 2013). Two of the others are non-parametric models derived using data-driven approaches (Derras et al., 2013; Hermkes et al., 2013) and the other model (Bora et al., 2013) makes predictions of response spectral accelerations using random-vibration theory based on empirical models for Fourier amplitude spectra and durations. Secondly, unlike the multi-year NGA project, which involved extensive interactions among developers and other project participants (leading to multiple iterations of the models), the models presented here were derived in a much shorter period and following limited communication among groups. Although the development of RESORCE was funded by SHARE and SIGMA, which led to some interactions among the model developers, this special issue is principally the fruit of parallel and independent efforts (by authors in five countries) rather than a coordinated national project. This means that the differences in the approaches used are larger than for NGA. It is possible that the use of multiple approaches for the models presented in this volume more effectively captures epistemic uncertainty in terms of the centre, the body and the range of technically-defensible interpretations of the available data (USNRC, 2012). Thirdly, the independent parameters used by the models presented here are: common among groups (all use only: 
moment magnitude, $\mathrm{M}_{\mathrm{w}}$; distance to the surface projection of the fault, $\mathrm{R}_{\mathrm{JB}}{ }^{10}$; the same style-offaulting classifications; and the average shear-wave velocity to $30 \mathrm{~m}, \mathrm{~V}_{\mathrm{S} 30}$ ) and fewer (e.g. data were insufficient to include terms involving sediment depth, $\mathrm{Z}_{1.0}$ or $\mathrm{Z}_{2.5}$, or depth to the top of rupture, $\mathrm{Z}_{\mathrm{TOR}}$ ) than in the NGA models. This makes comparisons among the models and their use in future seismic hazard assessments easier since no adjustments for differences in independent parameters (e.g. Bommer et al., 2005) are required. Lastly, no strict model requirements were agreed at the beginning of the derivation procedure, unlike those imposed on the NGA model developers, which means that the models presented here have varying ranges of applicability in terms of, for example, magnitude and distance.

Despite the differences between the NGA project and this special issue, the NGA comparison article by Abrahamson et al. (2008) is used as a template for this article comparing the five models presented in this issue, namely those by: Akkar et al. (2013a, b) (their model using $\mathrm{R}_{\mathrm{JB}}$ ), Bindi et al. (2013) (their model using $\mathrm{V}_{\mathrm{S} 30}$ directly ${ }^{11}$ ), Bora et al. (2013), Derras et al. (2013) and Hermkes et al. (2013). This decision means that comparisons between the figures presented here can be readily made to those shown in Abrahamson et al. (2008) because the same choices of independent parameters and the same axes and scales are used (also to help in making these comparisons the same figure numbering has been retained). Note that some of the graphs show predictions up to $M_{w} 8$, for consistency with Abrahamson et al. (2008), even though some developers do not recommend their models are applied for such large earthquakes (Table 1). To further facilitate comparisons with the NGA models, predictions from the GMPEs of Boore and Atkinson (2008) are included on the figures. This NGA model was chosen from among the five because it is the most similar to those presented in this special issue through its use of $\mathrm{R}_{\mathrm{JB}}$ and fewer independent variables, e.g. no terms using $\mathrm{Z}_{\mathrm{TOR}}$ or $\mathrm{Z}_{1.0}$ (or $\mathrm{Z}_{2.5}$ ) are included. Because the models presented here have fewer independent parameters and the aleatory variabilities (standard deviations) of the models are all homoscedastic (uniform for all independent and dependent variables) some figures drawn by Abrahamson et al. (2008) are not relevant and are not drawn. They are replaced with figures showing other features of the models that are not covered by the other graphs, for example the influence of style of faulting on ground-motion predictions (e.g. Bommer et al., 2003).

The next section presents the data selection criteria used by the different groups. The following sections compare different aspects of the models in terms of: attenuation with distance, scaling with

\footnotetext{
${ }^{10}$ Akkar et al. (2013a, b) also derived GMPEs using epicentral $\left(R_{\text {epi }}\right)$ and hypocentral $\left(R_{\text {hyp }}\right)$ distances. These are not considered in this article.

${ }^{11}$ Bindi et al. (2013) also derived GMPEs using hypocentral $\left(R_{\text {hyp }}\right)$ distance and EC8 site classes rather than $V_{530}$ directly. These models are not considered in this article.
} 
magnitude, style-of-faulting factors, site amplification, predicted response spectra and aleatory variability. The article ends with some brief conclusions.

\section{Data selection criteria}

All GMPE developers started with the same RESORCE archive, which is presented by Akkar et al. (2013a) in this special issue. At the time of model derivation this databank contained 5,882 mainlytriaxial accelerograms (from $0 \leq \mathrm{R} \leq 587 \mathrm{~km}$ ) from 1,814 earthquakes (with $2.8 \leq \mathrm{M}_{\mathrm{w}} \leq 7.8$ ) and 1,540 different strong-motion stations. The five groups of developers applied different selection and exclusion criteria, which led to them using between only $14 \%$ and $38 \%$ of the available accelerograms (see Table 1). The same magnitude ranges were used by all groups, except by Derras et al. (2013) who used a slightly lower minimum magnitude (3.6 rather than 4.0), to select their data and only Bindi et al. (2013) and Derras et al. (2013) varied from the distance cut-off of 200km (using $300 \mathrm{~km}$ and $547 \mathrm{~km}$, respectively, instead). None of the RESORCE developers used selection criteria based on earthquake type (e.g. mainshock, aftershock or swarm) or considered its influence on ground motions. Consequently all types of earthquakes (including aftershocks) were selected, unlike Boore and Atkinson (2008) who exclude this type of event when deriving their NGA model and other NGA models that included terms in their models to distinguish between mainshocks and aftershocks. As discussed by Douglas and Halldorsson (2010) there is considerable doubt over the classification of European earthquakes into mainshock, aftershock and swarm and their analysis using the data and model of Ambraseys et al. (2005) suggested that the influence of earthquake type on ground motions is limited. A similar conclusion is reached by Bindi et al. (2013) after examining the residuals for their model separated into mainshock and aftershock classes. The five model databases principally comprise records from normal and strike-slip earthquakes, with a smaller number of accelerograms from reverse-faulting events. The distribution of records by style-of-faulting is reasonably uniform with respect to magnitude but the largest $\left(\mathrm{M}_{\mathrm{w}}>7\right)$ earthquakes are mainly from strike-slip earthquakes in Turkey (Kocaeli and Düzce) and Iran (Manjil). The variation in the final databases principally results from the exclusion of data based on the filters used to process the accelerograms. The result of these various selection criteria are different sizes of databases used for the derivations of the five models (Table 1). All of the models were derived using roughly 1000 strong-motion records.

One major difference between the data used by the models compared here and that used for the NGA models is the large number of poorly-recorded earthquakes. This is indicated by the mean number of records per earthquake for the five RESORCE models being between 3.0 and 5.8 (Table 1) whereas the mean number of records per earthquake for the NGA models varies between 13.1 and 27.1. This difference implies that the terms of the models related to the earthquake source (e.g. style-of-faulting terms and between-event standard deviations) are more poorly constrained than they are in the NGA models, which, as shown below, leads to significant differences in these aspects of the models. The 
complexity of the source modelling in some of the NGA models, however, means that these models may suffer from trade-offs, for example between the effect of $Z_{T O R}$ and style-of-faulting.

\section{Attenuation with distance}

The decay with distance from the source for peak ground acceleration (PGA) and spectral acceleration for a structural period of $1 \mathrm{~s}$ and $5 \%$ critical damping [SA(1s)] can be seen in Figure 1, for $\mathrm{V}_{\mathrm{S} 30}=760 \mathrm{~m} / \mathrm{s}$, i.e. NEHRP B/C boundary (Building Seismic Safety Council, 2009) (soft rock, Eurocode 8 class B), and in Figure 2, for $\mathrm{V}_{\mathrm{S} 30}=270 \mathrm{~m} / \mathrm{s}$, i.e. NEHRP D (soft soil, Eurocode 8 class C). Generally the decay rates are similar as are the predicted ground motions, particularly for small and moderate events and PGA. Predictions from the models derived by standard regression techniques (Akkar et al., 2013a, b; Bindi et al., 2013) are comparable except at the limits of their applicability $\left(M_{w} 8\right.$ and close to the source of large earthquakes, $\left.R_{J B}<10 \mathrm{~km}\right)$. Bindi et al. (2013) include an anelastic attenuation ${ }^{12}$ term for short periods whereas Akkar et al. (2013a, b) tried including such a term but found that it converged to a non-physical value and hence they removed it from their functional form. Predictions from the nonparametric models show considerable variations and the model of Hermkes $e t$ al. (2013) shows a complex decay rate, with a change of slope (often flattening) starting around 50km. Despite all models having being derived from a common original archive (even if the final databases used differed), a factor of two difference in predicted median ground motions from the models is not uncommon, except for magnitudes and distance near the centre of the available data (e.g. $\left.M_{w} 6\right)$.

As is becoming commonly recognised and modelled, the decay of earthquake ground motions is magnitude dependent. This effect can be seen by comparing the decay rates for $M_{w} 5$ (roughly $1 / R^{1.5}$ for PGA) to those for $M_{w} 8$ (slower than 1/R). The predicted ground motions from the RESORCE models all decay more rapidly than those from the GMPEs of Boore and Atkinson (2008), particularly for PGA, which leads to much lower predicted ground motions at moderate distances (roughly 20$100 \mathrm{~km}$ ) from these models compared to Boore and Atkinson (2008). Boore and Atkinson (2008) note that their distance dependence for small earthquakes and long periods may be biased towards a decay that is less rapid than the true decay. The faster decay of ground motions in Italy (from where a considerable portion of the data used to develop the RESORCE models comes) than in California was previously noted by Scasserra et al. (2009).

\section{Magnitude scaling}

The magnitude scaling of the five models show the expected behaviour of higher scaling at long structural periods (Figure 3). All models show nonlinear magnitude scaling with, generally, lower

\footnotetext{
${ }^{12}$ The expression 'anelastic attenuation' is only strictly valid for GMPEs for Fourier amplitudes and not response spectral ordinates.
} 
dependence of ground motions on magnitude for large events. This nonlinear behaviour is expected from physical models (e.g. Douglas and Jousset, 2011). Some studies (e.g. Schmedes and Archuleta, 2008) provide physical arguments for oversaturation of short-period ground motions for large earthquakes (i.e. ground motions that decrease as magnitude increases). This effect is not seen for any of the final RESORCE models for magnitudes within their range of applicability. However, when Akkar et al. (2013a, b) included a cubic magnitude term they found that the obtained model predicted oversaturation for $\mathrm{M}_{\mathrm{w}}>7.25$, which they considered physically unrealistic and hence they finally adopted a functional form that did not allow such oversaturation. They note, however, that due to a lack of data from large earthquakes in Europe and the Middle East there is considerable epistemic uncertainty in magnitude scaling for $\mathrm{M}_{\mathrm{w}}>7.5$ and hence they suggest including additional branches in a logic tree to account for this uncertainty. As for the distance decay, within the magnitude range that is well covered by data $\left(M_{w} 5\right.$ to 7$)$ the models predict similar spectral accelerations whereas for larger earthquakes the models differ greatly, depending on whether they are solely driven by the data or the functional form assumed. The magnitude scaling of the RESORCE models is broadly in line with that predicted by the Boore and Atkinson (2008) GMPEs, although because of the lower attenuation predicted by this model there is a considerable offset in the predictions at the considered distance of $30 \mathrm{~km}$.

\section{Style-of-faulting factors}

The effect of style of faulting (faulting mechanism) on strong ground motion was highlighted by the review of Bommer et al. (2003), who compared predictions of the reverse-to-strike-slip spectral ratios $\left(F_{R: S S}\right)$ for various GMPEs (their Figure 3) and who also discussed the limited number of estimates of the ratio of normal-to-strike-slip motions $\left(\mathrm{F}_{\mathrm{N}: \mathrm{SS}}\right)$ then available. In the decade since then many more estimates of these factors have been published as part of GMPEs, including in the NGA models, but they still show considerable dispersion. Nevertheless, as shown by the example of the Boore and Atkinson (2008) ratios plotted on Figure 4, reverse-faulting events are often thought to generate slightly higher amplitude motions that strike-slip earthquakes that in turn are slightly higher than motions from normal-faulting earthquakes.

Figure 4 compares $\mathrm{F}_{\mathrm{R}: \mathrm{Ss}}$ and $\mathrm{F}_{\mathrm{N}: s s}$ for the five RESORCE models [and those of Boore and Atkinson (2008)]. All developers, except Hermkes et al. (2013), assumed ratios that are independent of magnitude and distance. Using a nonparametric approach Hermkes et al. (2013) find ratios that depend weakly on these variables. These ratios are generally quite close to unity (i.e. rupture mechanism has no effect on spectral accelerations) but two models (Bindi et al., 2013; Hermkes et al., 2013) show large values for $\mathrm{F}_{\mathrm{R}: S S}(>1.25)$, particularly those of Hermkes et al. (2013), whose ratios reach over two. $\mathrm{F}_{\mathrm{N}: \mathrm{ss}}$ are generally within 0.1 of unity except, again, for Hermkes et al. (2013) at moderate and long periods where the ratios reach 1.5 . The overall observation that the style of faulting has a limited 
impact on spectral accelerations is in line with the findings from previous studies, including those associated with the NGA models. The usual order of which style of faulting leads to the highest and lowest motions is reversed in the model of Derras et al. (2013), which predicts that normal-faulting events cause higher SAs than reverse-faulting earthquakes. One possible reason for this is that only 93 of the 1,088 records used to derive this model are from reverse-faulting events (compared to 540 from normal and 455 from strike-slip earthquakes) and, in addition, each earthquake is only associated with on average 3.4 records (Table 1) and hence the style-of-faulting factors are poorly constrained. In view of this, the style-of-faulting factors implied by the model of Derras et al. (2013) are not recommended for application. Compared with the NGA database, RESORCE is much richer in data from normalfaulting earthquakes, e.g. less than 3\% of the records used by Boore and Atkinson (2008) come from normal events, and consequently the estimates of $\mathrm{F}_{\mathrm{N}: \mathrm{ss}}$ from the RESORCE models are much better constrained.

\section{Scaling with $V_{S 30}$}

All models (Figure 5) predict an overall inverse dependence on $\mathrm{V}_{\mathrm{S} 30}$, i.e. as $\mathrm{V}_{\mathrm{S} 30}$ increases ground motions decrease, even if no functional form was imposed. In addition, the models predict a stronger dependence on $\mathrm{V}_{\mathrm{S} 30}$ for longer structural periods (Figure 5, Figure 6). All of the models except those of Bindi et al. (2013) and Bora et al. (2013) include nonlinear site behaviour, i.e. lower amplifications on soft soils (low $\mathrm{V}_{\mathrm{S} 30}$ ) for stronger shaking (Figure 5, Figure 6). However, once again the dispersion in the predictions is quite large, particularly at longer periods.

The ratios of spectral accelerations on soft soil to rock reach their peak for a structural period of around 1s with ratios of three or even higher (up to about 5.5 for Hermkes et al., 2013) (Figure 6), although they show considerable variation among models. Similarly the peak in the stiff-soil-to-rock ratios is at about $1 \mathrm{~s}$ but the peak ratios are lower (around 1.5) and show smaller dispersion. These ratios are similar to those represented in a similar plot (their Figure 10) by Ambraseys et al. (2005). One difference with the NGA models, however, is that the peak amplification occurs in the NGA models at a longer period (>3s) [see, e.g., the curves for Boore and Atkinson (2008) in Figure 6], which could be related to soil profiles that are deeper on average in California than in Europe and the Middle East (Stewart et al., 2012) or to smaller sedimentary basins in Europe compared to California that give rise to 2D-3D basin effects at shorter periods. Also the long-period site amplifications predicted by the Boore and Atkinson (2008) model are generally lower than those predicted by the RESORCE models.

\section{Predicted response spectra}

The models all predict similar response spectra on NEHRP B/C boundary sites for $\mathrm{M}_{\mathrm{w}} 5$ to 7 at $\mathrm{R}_{\mathrm{JB}}=10 \mathrm{~km}$ (Figure 7); any differences in the models become apparent at large magnitudes, longer 
distances and for softer sites (see, e.g., Figures 1 and 2). For the largest events, the functional forms used to develop the models of Akkar et al. (2013a, b), Bindi et al. (2013), Bora et al. (2013) and Hermkes et al. (2013) allow evaluation up to $\mathrm{M}_{\mathrm{w}} 8$ whereas the model of ( Derras et al. (2013) should not be used for such magnitudes. The periods of the plateaus in the spectra do not show strong magnitude dependency. Predictions from the GMPEs of Boore and Atkinson (2008) at this distance for all magnitudes fall roughly in the middle of the predictions from the RESORCE models but because of the lower attenuation predicted by this model the predicted spectra for longer distances are higher than those predicted by the RESORCE models (not shown here).

The predicted spectra for soft soil sites show a much broader plateau and greater dispersion than in the predicted spectra on rock (Figure 8), which is due to the strong long-period site amplifications predicted by some models (Figure 6). Again a factor of two in the predicted spectral accelerations can be seen between the highest and lowest predictions.

\section{Aleatory varability}

As noted above, all models predict homoscedastic aleatory variability (standard deviation, sigma) and consequently only a single figure is required to summarise this aspect of the models (Figure 9). As Akkar et al. (2013a, b) note there is limited data from larger earthquakes and consequently the apparent magnitude dependency seen within their between-event residuals may not represent the true aleatory variability at large magnitudes. Consequently they assumed magnitude-independent sigmas. Similar arguments hold for the other models. The sigmas fall into two groups: Bora et al. (2013), which has slightly higher values, and the other four models. This difference is related to higher values of the between-event (tau) standard deviations whilst the within-event (phi) standard deviations are similar. The sigmas show similar dependence on period with a first peak between 0.1 and $0.2 \mathrm{~s}$ (near the plateau of predicted response spectra) and then a further increase in sigma as period increases. However, the period dependency is quite limited with less than a $20 \%$ difference between the lowest and the highest sigma.

The values of tau for the models of Akkar et al. (2013a, b), Derras et al. (2013) and Hermkes et al. (2013) are similar to those of the NGA models although slightly higher [see, e.g., the curve for Boore and Atkinson (2008) shown on Figure 9], whereas the taus of Bindi et al. (2013) and Bora et al. (2013) are larger. The values of phi of the different models are slightly (by about $0.1 \ln$ units for moderate magnitudes) higher than those of the NGA models [again, see the curve for Boore and Atkinson (2008) on Figure 9], which leads to overall sigmas that are also about $0.1 \mathrm{ln}$ units higher. The NGA models of aleatory variability also do not show a strong period dependence. The higher estimates of aleatory variability for the RESORCE models compared with the sigmas of the NGA models could be related to: a) truly higher variability in ground-motion databases in Europe and the Middle East (caused by, e.g., mixing together of data from a wide geographical region with different tectonics and 
geology); b) the use of more data from small earthquakes whose motions are possibly intrinsically more variable than those from large events because of, e.g., higher variability in stress drops; or c) problems with the metadata in RESORCE, particularly for small events (or more likely a mixture of these reasons). (Insufficiently complex functional forms for the RESORCE models cannot explain this difference because it is apparent even for the non-parametric models). One aspect of the metadata that could be revisited in future models for Europe and the Middle East, particularly for applications below $\mathrm{M}_{\mathrm{w}}$ 5.5, is the use of moment magnitude (sometimes obtained by conversions from other magnitude scales) rather than local magnitude $\left(\mathrm{M}_{\mathrm{L}}\right)$ for the smaller earthquakes. It was shown by Bindi et al. (2007), for north-western Turkey, that the use of $\mathrm{M}_{\mathrm{L}}$ for small earthquakes leads to lower estimates of between-event variability (tau) compared to using $\mathrm{M}_{\mathrm{w}}$. This is because corner frequencies for such earthquakes are generally higher than $1 \mathrm{~Hz}$, which is the frequency range at which $\mathrm{M}_{\mathrm{L}}$ is measured whereas $M_{w}$ is measuring energy at frequencies below the corner and hence it is a poorer measure of the size of such events. Therefore, it could be envisaged that $M_{L}$ is used below, say, $M_{w} 5.5$ for the derivation of GMPEs and then in applications the local magnitude scale for that region is used to evaluate the model. Sabetta and Pugliese (1987) adopted a similar composite magnitude scale $\left(\mathrm{M}_{\mathrm{L}}\right.$ below M 5.5 and surface-wave magnitude, $\mathrm{M}_{\mathrm{s}}$, above this limit) when deriving their GMPEs for Italy.

\section{Conclusions}

In this article, various aspects of the five ground-motion models that are described in other articles in this special issue have been compared. Despite all the developers having started with the same common strong-motion archive and having used the same independent parameters, the predicted spectral accelerations from the models show significant differences, which can be related to varying data selection criteria and derivation techniques. All aspects of the models for the median ground motions (magnitude scaling, style-of-faulting factors, distance decay and site amplification) show variation from one model to the next. These differences when combined lead to variations in the predicted response spectral accelerations for scenarios of interest of more than a factor of two. These differences demonstrate that epistemic uncertainty in ground-motion prediction in Europe and the Middle East remains large and it cannot be explained by differences in the metadata of the strongmotion records used or different sets of independent parameters (e.g. hypocentral distance rather than Joyner-Boore distance or surface-wave magnitude rather than moment magnitude). One of the reasons for this large epistemic uncertainty is that a given earthquake in Europe and the Middle East is, on average, recorded by fewer strong-motion instruments than in California, Taiwan and Japan and hence the aspects of the models related to source effects are less well constrained.

The aleatory variabilities are slightly higher than those associated with the NGA models, again (e.g. Strasser et al., 2009) showing that this aspect of ground-motion modelling is stable within a narrow band ( \pm 0.2 ln units) around 0.7 (for PGA). In particular, estimates of the within-event variability (phi) 
show little variation from one study to the next. The between-event variability (tau), however, can be significantly affected by the inclusion of data from smaller (less well-studied) earthquakes. Further studies to constrain the value of tau for European events are, therefore, recommended.

The five models presented in this volume should be of considerable value for seismic hazard assessments in Europe and the Middle East, providing both state-of-the-art predictions of spectral accelerations and a basis for quantifying epistemic uncertainty in those predictions.

\section{Acknowledgements}

The work presented in this article was partially funded by the SHARE (Seismic Hazard Harmonization in Europe) Project funded under contract 226967 of the EC-Research Framework Programme FP7 and by the task 'Reference database for seismic ground motion in Europe' of the SIGMA (Seismic Ground Motion Assessment) project. We thank the personnel of the organisations operating seismological stations and freely disseminating their ground-motion data and related metadata, without which the derivation of the ground-motion models compared here would have been impossible. Finally, we thank an anonymous reviewer for their constructive comments on a previous version of this article.

\section{References}

Abrahamson, N. A., Youngs, R. R. (1992), A stable algorithm for regression analyses using the random effects model, Bulletin of the Seismological Society of America, 82(1), 505-510.

Abrahamson, N., Atkinson, G., Boore, D., Bozorgnia, Y., Campbell, K., Chiou, B., Idriss, I. M., Silva, W., Youngs, R. (2008), Comparisons of the NGA ground-motion relations, Earthquake Spectra, 24(1), 45-66, doi: 10.1193/1.2924363.

Akkar, S., Sandıkkaya, M. A., Bommer, J. J. (2013a), Empirical ground-motion models for point- and extended-source crustal earthquake scenarios in Europe and the Middle East, Bulletin of Earthquake Engineering, this issue, doi: 10.1007/s10518-013-9461-4.

Akkar, S., Sandıkkaya, M. A., Bommer, J. J. (2013b), Erratum: Empirical ground-motion models for point- and extended-source crustal earthquake scenarios in Europe and the Middle East, Bulletin of Earthquake Engineering, this issue.

Akkar, S., Sandıkkaya, M. A, Șenyurt, M., Azari, A. S., Ay, B. Ö., Traversa, P., Douglas, J., Cotton, F., Luzi, L., Hernandez, B., Godey, S. (2013c), Reference database for seismic ground-motion in Europe (RESORCE), Bulletin of Earthquake Engineering, this issue, doi: 10.1007/s10518-013-9506-8.

Ambraseys, N. N., Douglas, J., Sarma, S. K., Smit, P. M. (2005), Equations for the estimation of strong ground motions from shallow crustal earthquakes using data from Europe and the Middle East: 
Horizontal peak ground acceleration and spectral acceleration, Bulletin of Earthquake Engineering, 3(1), 1-53, doi: 10.1007/s10518-005-0183-0.

Bindi, D., Massa, M., Luzi, L., Ameri, G., Pacor, F., Puglia, R., Augliera, P. (2013), Pan-European ground-motion prediction equations for the average horizontal component of PGA, PGV, and 5\%Damped PSA at spectral periods up to $3.0 \mathrm{~s}$ using the RESORCE dataset, Bulletin of Earthquake Engineering, submitted to this issue.

Bindi, D., Parolai, S., Grosser, H., Milkereit, C., Durukal, E. (2007), Empirical ground-motion prediction equations for northwestern Turkey using the aftershocks of the 1999 Kocaeli earthquake. Geophysical Research Letters, 34(L08305).

Bommer, J. J., Douglas, J., Strasser, F. O. (2003), Style-of-faulting in ground-motion prediction equations, Bulletin of Earthquake Engineering, 1(2), 171-203.

Bommer, J. J., Scherbaum, F., Bungum, H., Cotton, F., Sabetta, F., Abrahamson, N. A. (2005), On the use of logic trees for ground-motion prediction equations in seismic-hazard analysis, Bulletin of the Seismological Society of America, 95(2), 377-389, doi: 10.1785/0120040073.

Boore, D. M., Atkinson, G. M. (2008), Ground-motion prediction equations for the average horizontal component of PGA, PGV, and 5\%-damped PSA at spectral periods between 0.01s and 10.0s, Earthquake Spectra, 24(1), 99-138.

Bora, S. S., Scherbaum, F., Stafford, P. J., Kuehn, N. (2013), Fourier spectral- and duration models for the generation of response spectra adjustable to different source-, propagation-, and site conditions, Bulletin of Earthquake Engineering, this issue, doi: 10.1007/s10518-013-9482-z.

Building Seismic Safety Council (2009), 2009 NEHRP Recommended Seismic Provisions For New Buildings and Other Structures: Part 1, Provisions, Federal Emergency Management Agency (P-750), Washington D.C.

Castellaro, S., Mulargia, F., Rossi, P. L. (2008), V $\mathrm{S} 30_{0}$ Proxy for seismic amplification? Seismological Research Letters, 79(4), 540-543, doi: 10.1785/gssrl.79.4.540.

Chiou, B., Darragh, R., Gregor, N., Silva, W. (2008), NGA project strong-motion database, Earthquake Spectra, 24(1), 23-44, doi: 10.1193/1.2894831.

Derras, B., Cotton, F., Bard, P.-Y. (2013), Towards fully data driven ground-motion prediction models for Europe, Bulletin of Earthquake Engineering, this issue, doi: 10.1007/s10518-013-9481-0.

Douglas, J. (2010), Consistency of ground-motion predictions from the past four decades, Bulletin of Earthquake Engineering, 8(6), 1515-1526, doi: 10.1007/s10518-010-9195-5. 
Douglas, J., Halldórsson, B. (2010), On the use of aftershocks when deriving ground-motion prediction equations, 9th US National and 10th Canadian Conference on Earthquake Engineering: Reaching Beyond Borders, paper ID 220.

Douglas, J., Jousset, P. (2011), Modeling the difference in ground-motion magnitude-scaling in small and large earthquakes, Seismological Research Letters, 82(4), 504-508, doi: 10.1785/gssrl.82.4.504.

Hermkes, M., Kuehn, N. M., Riggelsen, C. (2013), Simultaneous quantification of epistemic and aleatory uncertainty in GMPEs using Gaussian process regression, Bulletin of Earthquake Engineering, this issue, doi: .

Petersen, M. D., Frankel, A. D., Harmsen, S. C., Mueller, C. S., Haller, K. M., Wheeler, R. L., Wesson, R. L., Zeng, Y., Boyd, O. S., Perkins, D. M., Luco, N., Field, E. H., Wills, C. J., Rukstales, K. S. (2008), Documentation for the 2008 Update of the United States National Seismic Hazard Maps, Open-File Report 2008-1128, U.S. Department of the Interior, U.S. Geological Survey, 61 pp.

Power, M., Chiou, B., Abrahamson, B., Bozorgnia, Y., Shantz, T., Roblee, C. (2008), An overview of the NGA project, Earthquake Spectra, 24(1), 3-21, doi: 10.1193/1.2894833.

Sabetta, F., Pugliese, A. (1987), Attenuation of peak horizontal acceleration and velocity from Italian strong-motion records, Bulletin of the Seismological Society of America, 77(5), 1491-1513.

Scasserra, G., Stewart, J.P., Bazzurro, P., Lanzo, G., Mollaioli, F. (2009), A comparison of NGA ground-motion prediction equations to Italian data, Bulletin of the Seismological Society of America, 99(5), 2961-2978.

Schmedes, J., Archuleta, R. J. (2008), Near-source ground motion along strike-slip faults: Insights into magnitude saturation of PGV and PGA, Bulletin of the Seismological Society of America, 98(5), 2278-2290, doi: 10.1785/0120070209.

Stafford, P. J., Strasser, F. O., Bommer, J. J. (2008), An evaluation of the applicability of the NGA models to ground-motion prediction in the Euro-Mediterranean region, Bulletin of Earthquake Engineering, 6(2), 149-177.

Stewart, J.P., Douglas, J., Javanbarg, M. B., Di Alessandro, C., Bozorgnia, Y., Abrahamson, N. A., Boore, D. M., Campbell, K. W., Delavaud, E., Erdik, M., Stafford, P. J. (2012), Selection of a global set of ground motion prediction equations: Work undertaken as part of Task 3 of the GEM-PEER Global GMPEs project, PEER Report 2012/xx, Pacific Earthquake Engineering Research Center.

Strasser, F., Abrahamson, N.A., Bommer, J.J. (2009), Sigma: issues, insights, and challenges, Seismological Research Letters, 80(1), 40-56. 
389 USNRC (2012). Practical Implementation Guidelines for SSHAC Level 3 and 4 Hazard Studies.

390 NUREG-2117, US Nuclear Regulatory Commission, Washington, DC.

391 

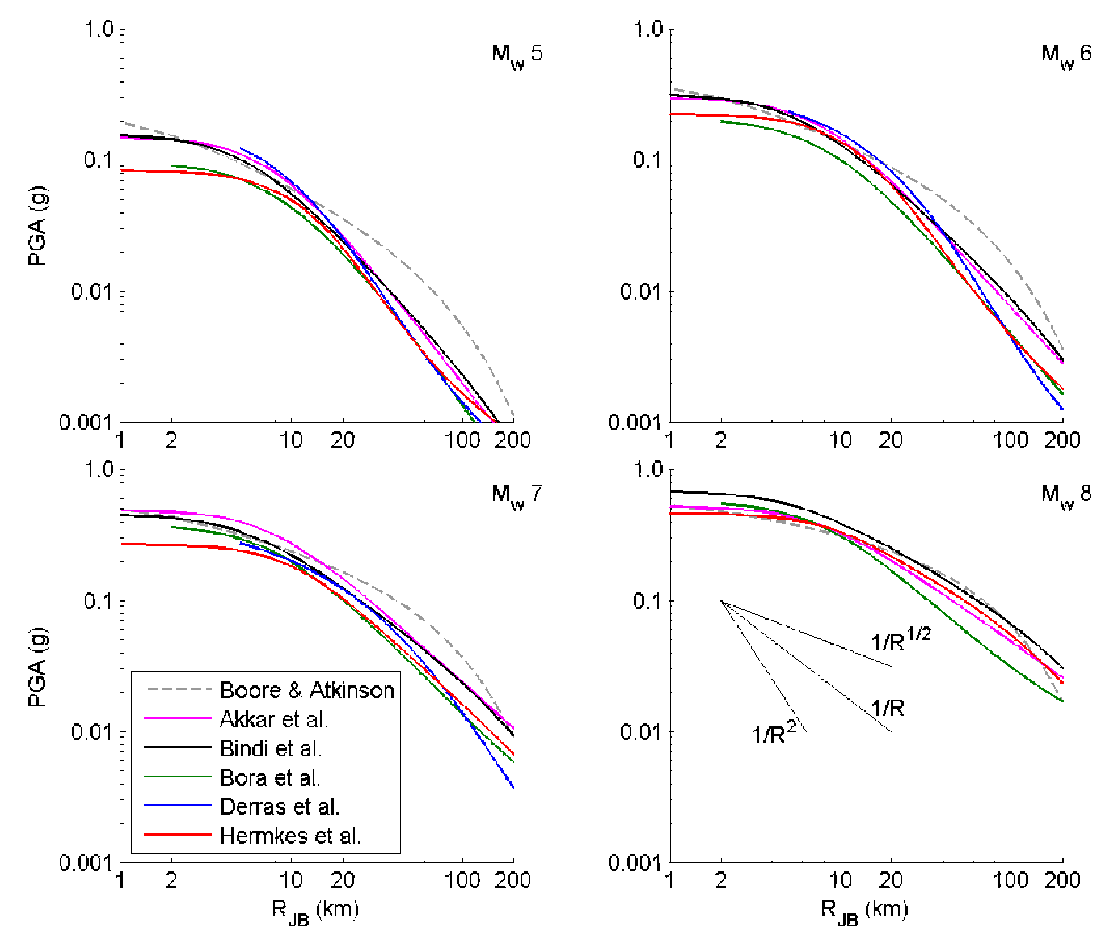

a)
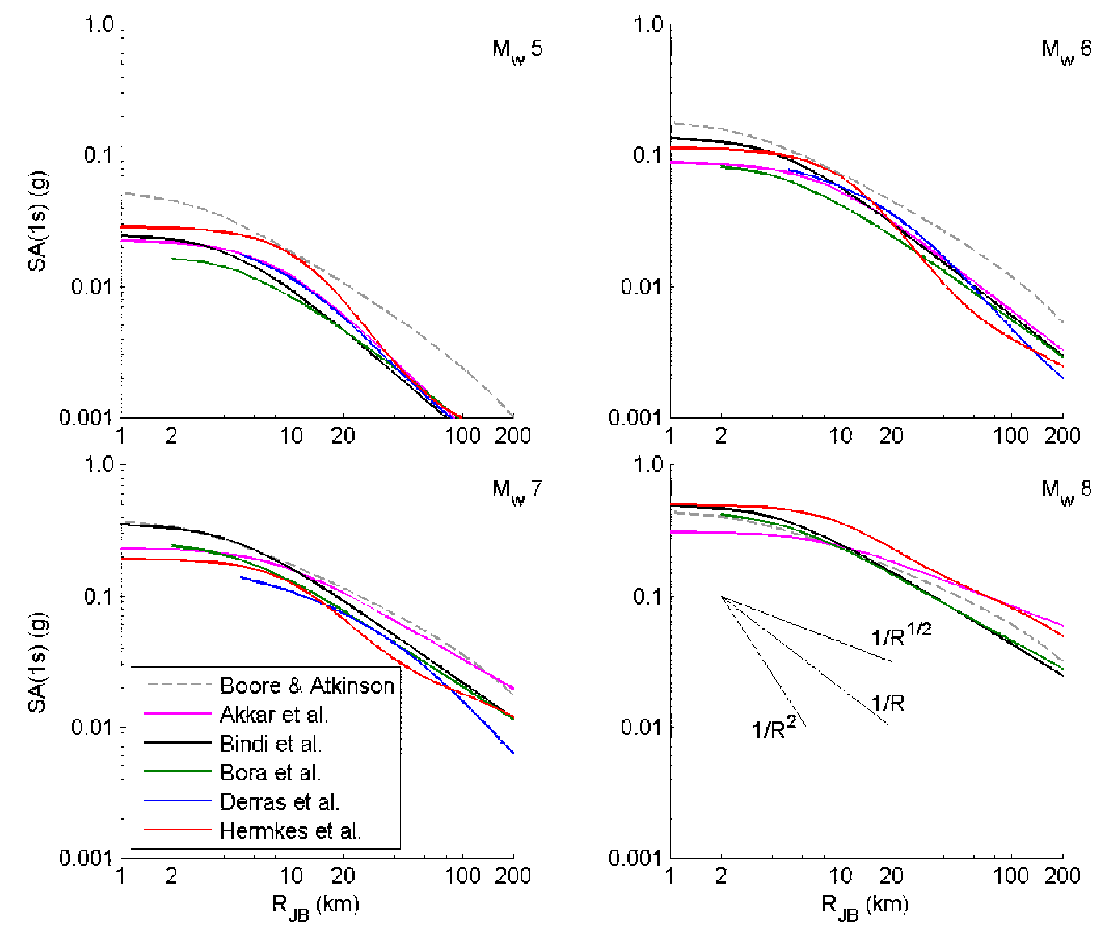

b)

395 Figure 1: Comparison of distance scaling for strike-slip earthquakes for $V_{S 30}=760 \mathrm{~m} / \mathrm{s}(\mathrm{NEHRP} \mathrm{B/C}$ boundary) for $M_{w} 5$ (top left), 6 (top right), 7 (bottom left) and 8 (bottom right) for a) PGA and b) $S A(1 s)$. The predictions from the model of Derras et al. (2013) are not shown for $M_{w} 8$ since this is outside its range of applicability. The other models are shown for this magnitude even though some developers do not recommend their application for such large events. 

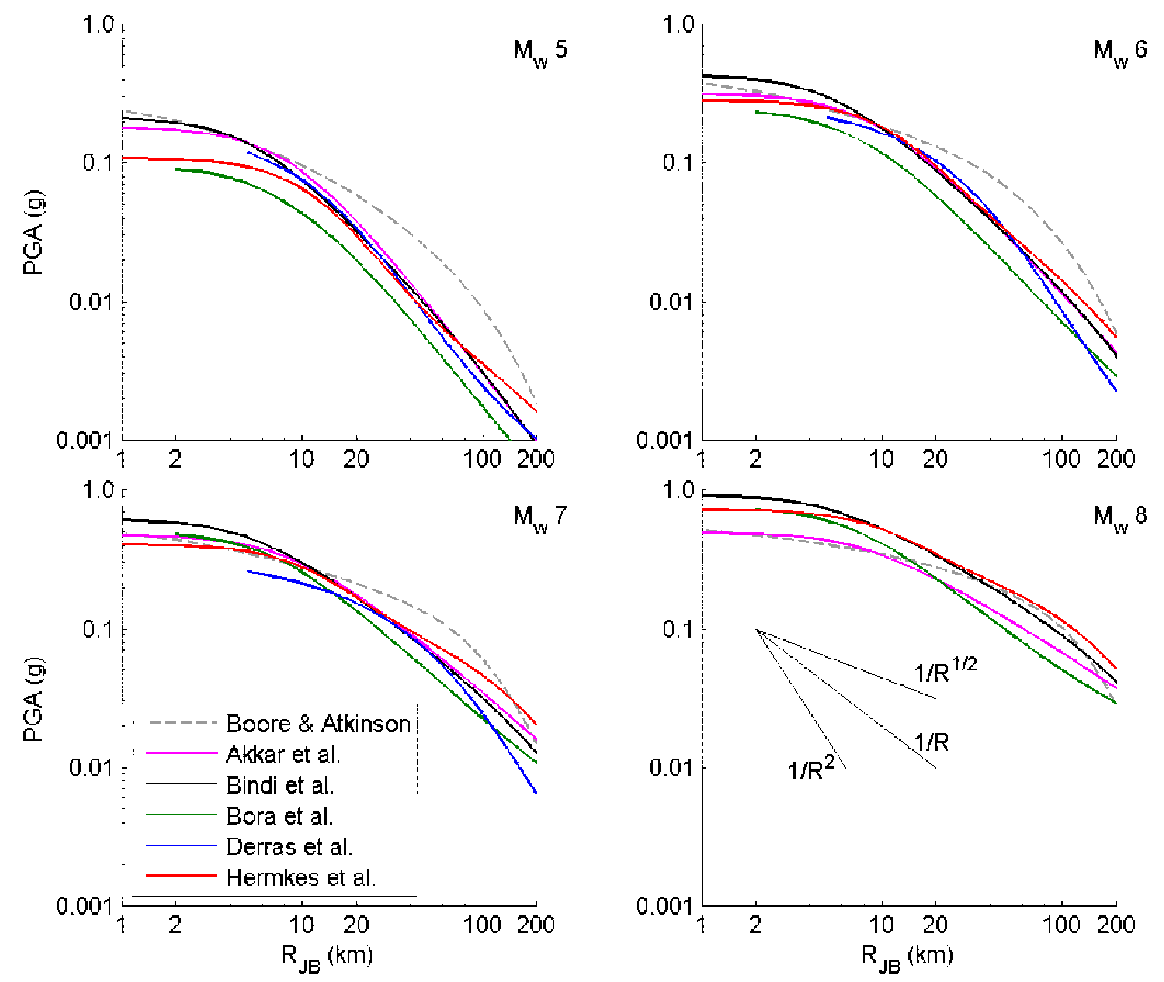

a)
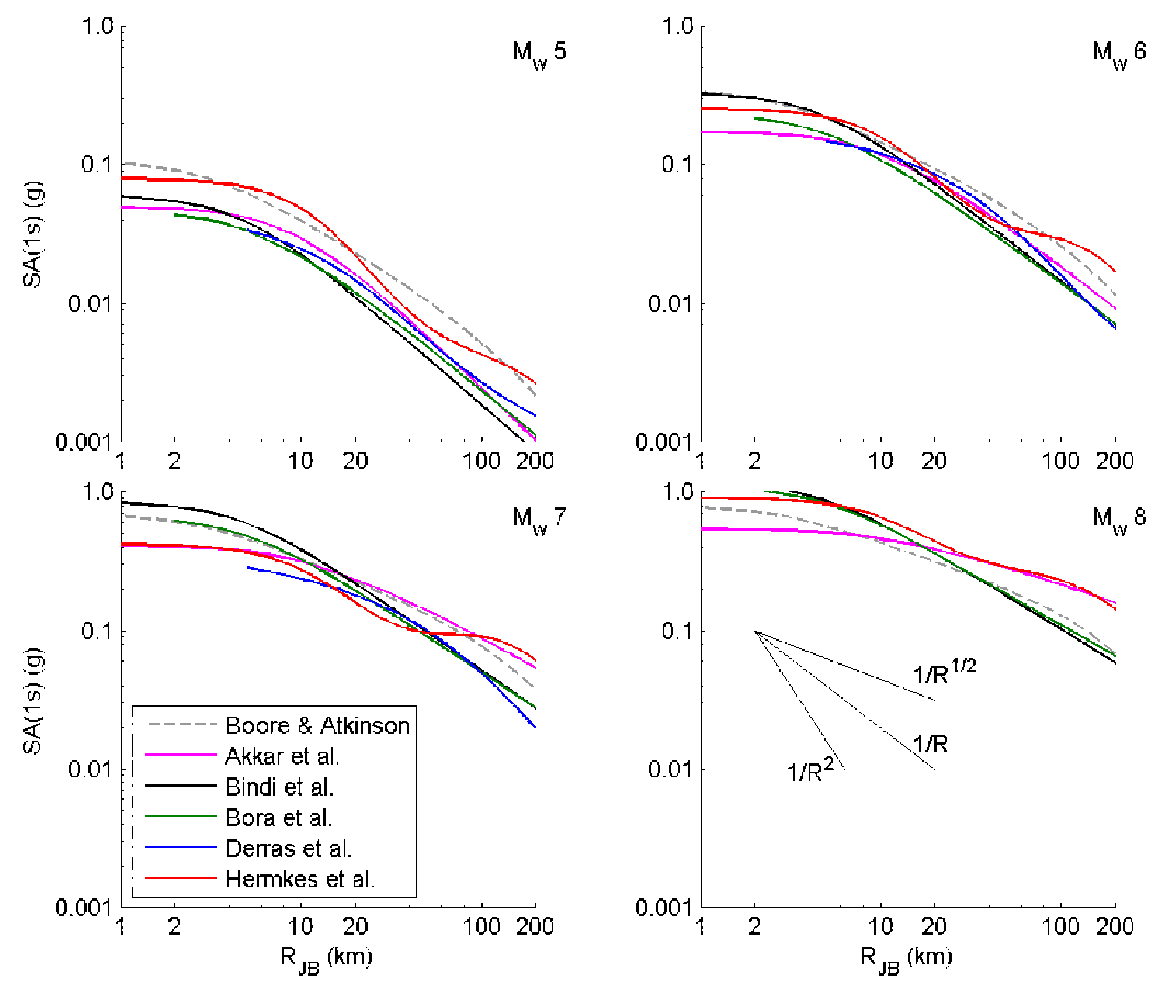

b)

402 Figure 2: Comparison of distance scaling for strike-slip earthquakes for $V_{S 30}=270 \mathrm{~m} / \mathrm{s}$ (NEHRP D) for $403 M_{w} 5$ (top left), 6 (top right), 7 (bottom left) and 8 (bottom right) for a) PGA and b) SA(1s). The 404 predictions from the model of Derras et al. (2013) are not shown for $M_{w} 8$ since this is outside its 405 range of applicability. The other models are shown for this magnitude even though some developers do not recommend their application for such large events. 


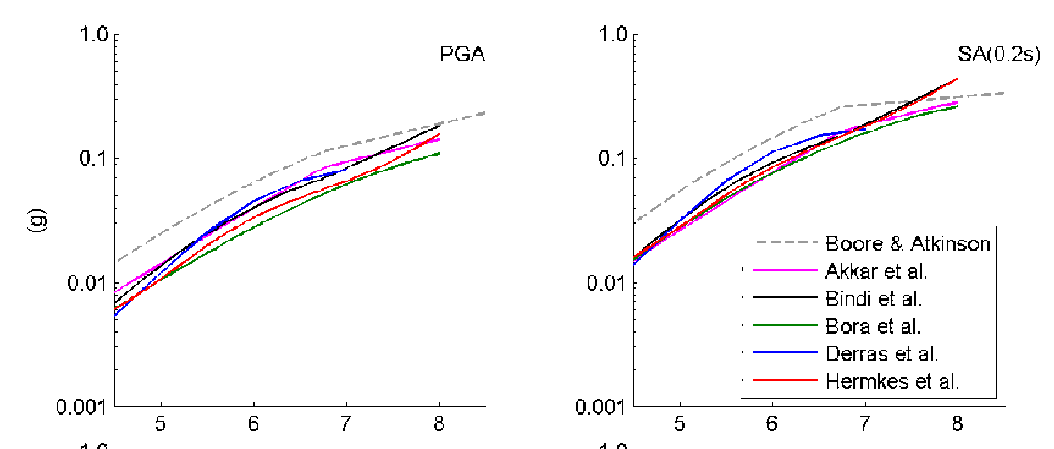

408 Figure 3: Comparison of magnitude scaling of the median ground motion for strike-slip earthquakes 409 and $V_{S 30}=760 \mathrm{~m} / \mathrm{s}\left(N E H R P B / C\right.$ boundary) at $R_{J B}=30 \mathrm{~km}$ for PGA (top left), $S A(0.2 \mathrm{~s})$ (top right), $410 S A(1.0 s)$ (bottom left) and $S A(3.0 s)$ (bottom right). Predictions are generally shown up to $M_{w} 8$ even

411 though some developers do not recommend their models for such large events.
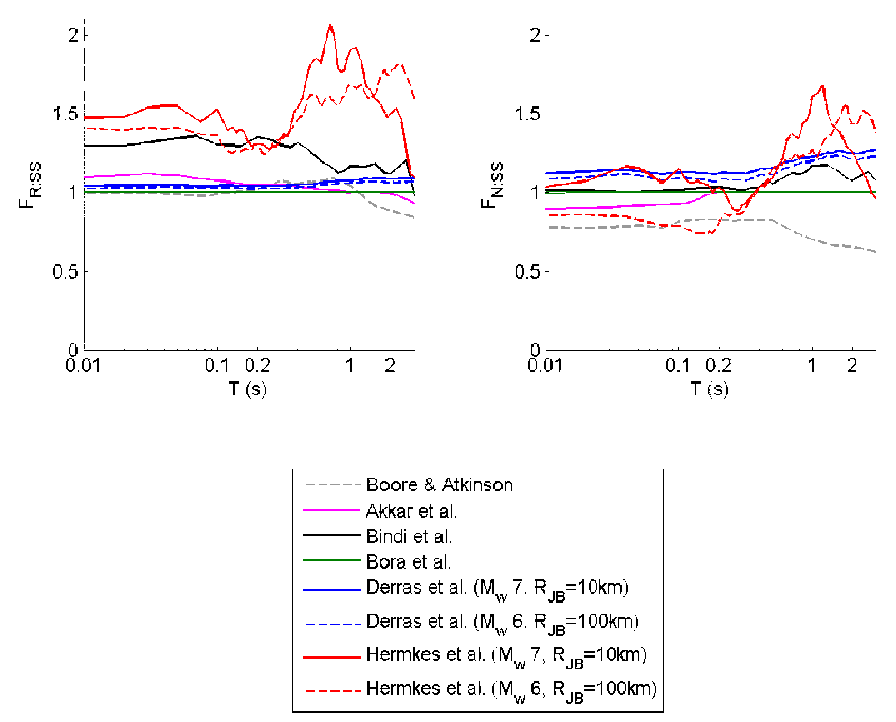

413 Figure 4: Comparison of style-of-faulting factors for $S A:$ a) ratio of reverse to strike-slip $\left(F_{R: S S}\right)$ and $\left.b\right)$ 414 ratio of normal to strike-slip $\left(F_{N: S S}\right)$. Ratios are scenario-independent except for those of Hermkes et 415 al. (2013). The predictions of Bora et al. (2013) are independent of the style of faulting. $F_{N: S S}$ of Akkar 416 et al. equals unity for $T>0.2 s$ and therefore this curve is under that of Bora et al. (2013) for these 417 periods. 

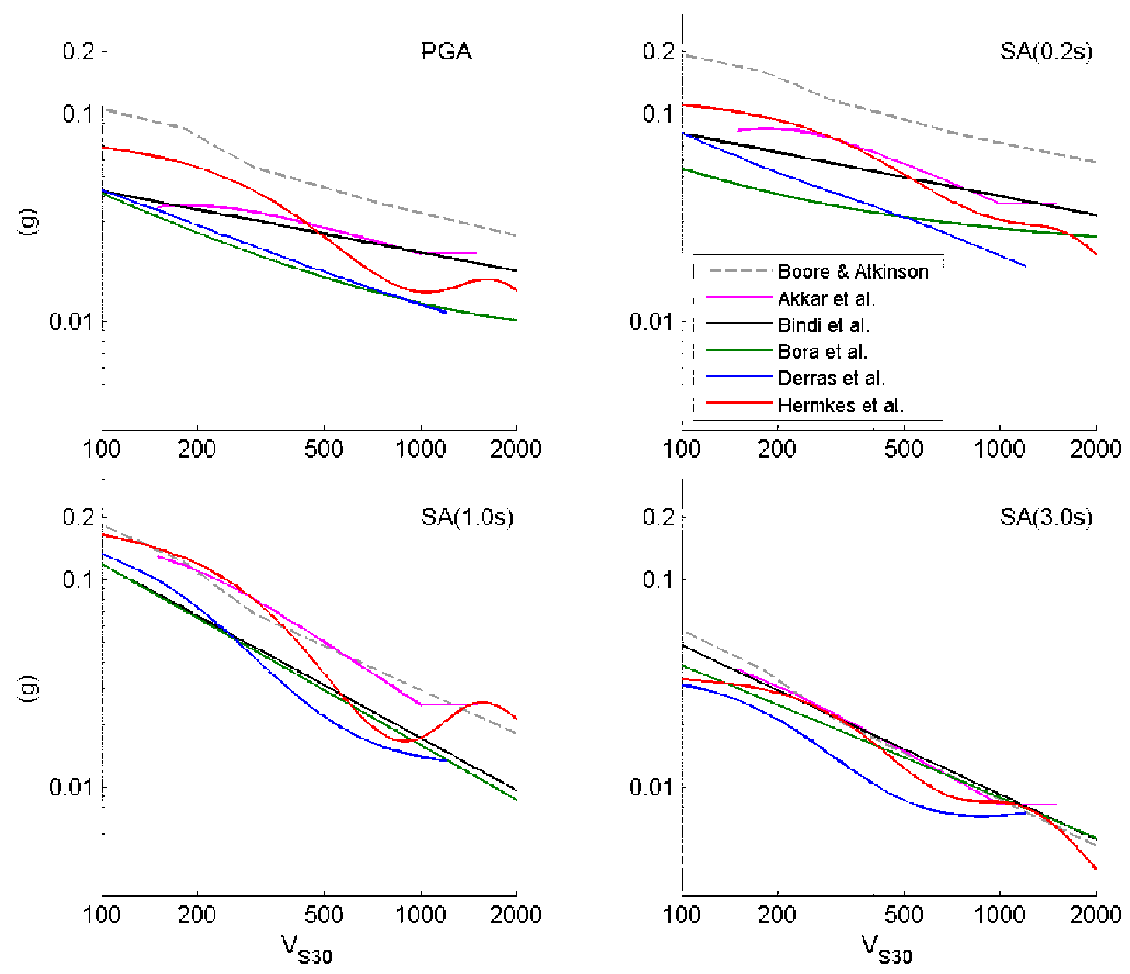

a)
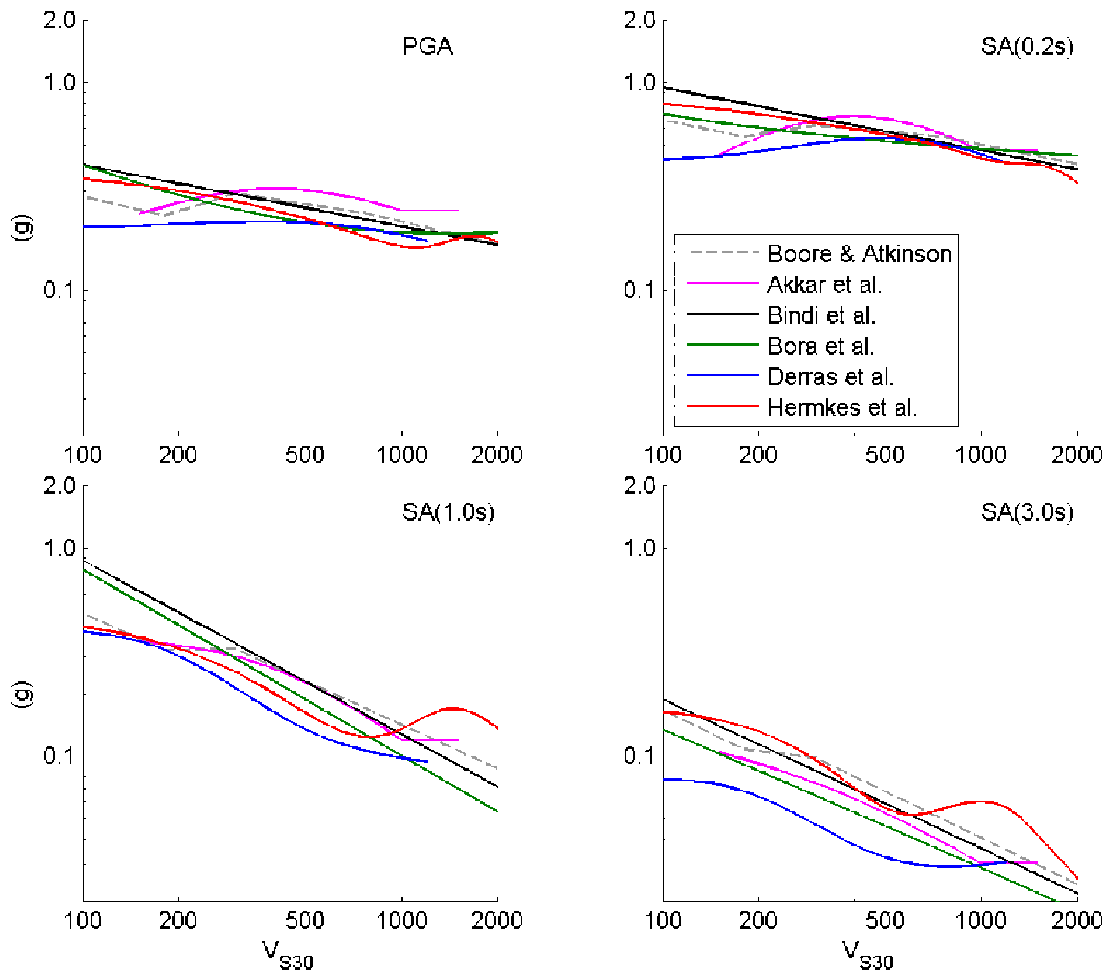

b)

420 Figure 5 Comparison of $V_{S 30}$ scaling of the median ground motion for $M_{w} 7$ strike-slip earthquakes for 421 PGA (top left), SA(0.2s) (top right), SA(1.0s) (bottom left) and SA(3.0s) (bottom right) at: 422 a) $R_{J B}=100 \mathrm{~km}$ and $\left.b\right) R_{J B}=10 \mathrm{~km}$. 

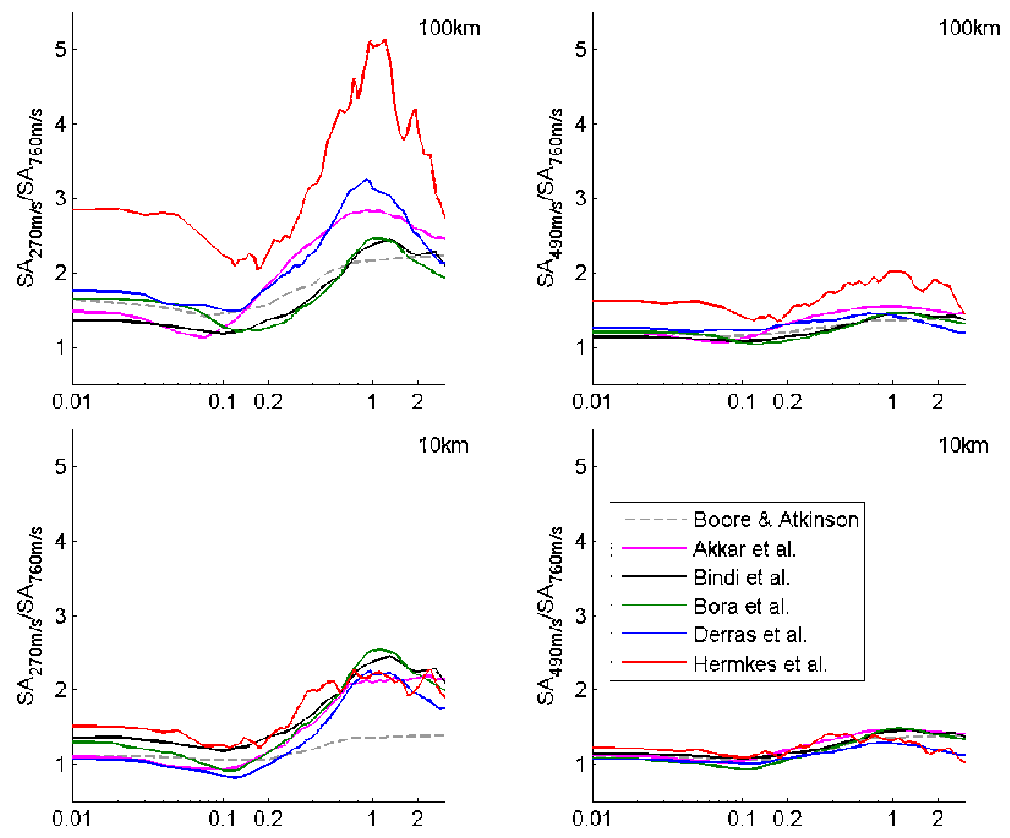

424 Figure 6: Comparison of ratios between $S A$ for $V_{S 30}=270 m / s$ (NEHRP D) (left) and SA for $425 V_{S 30}=490 \mathrm{~m} / \mathrm{s}(\mathrm{NEHRP} C)($ right $)$ to $S A$ for $V_{S 30}=760 \mathrm{~m} / \mathrm{s}$ for $M_{w} 7$ (strike-slip) at $R_{J B}=100 \mathrm{~km}($ top $)$ and $426 \quad M_{w} 7$ (strike-slip) at $R_{J B}=10 \mathrm{~km}$ (bottom).
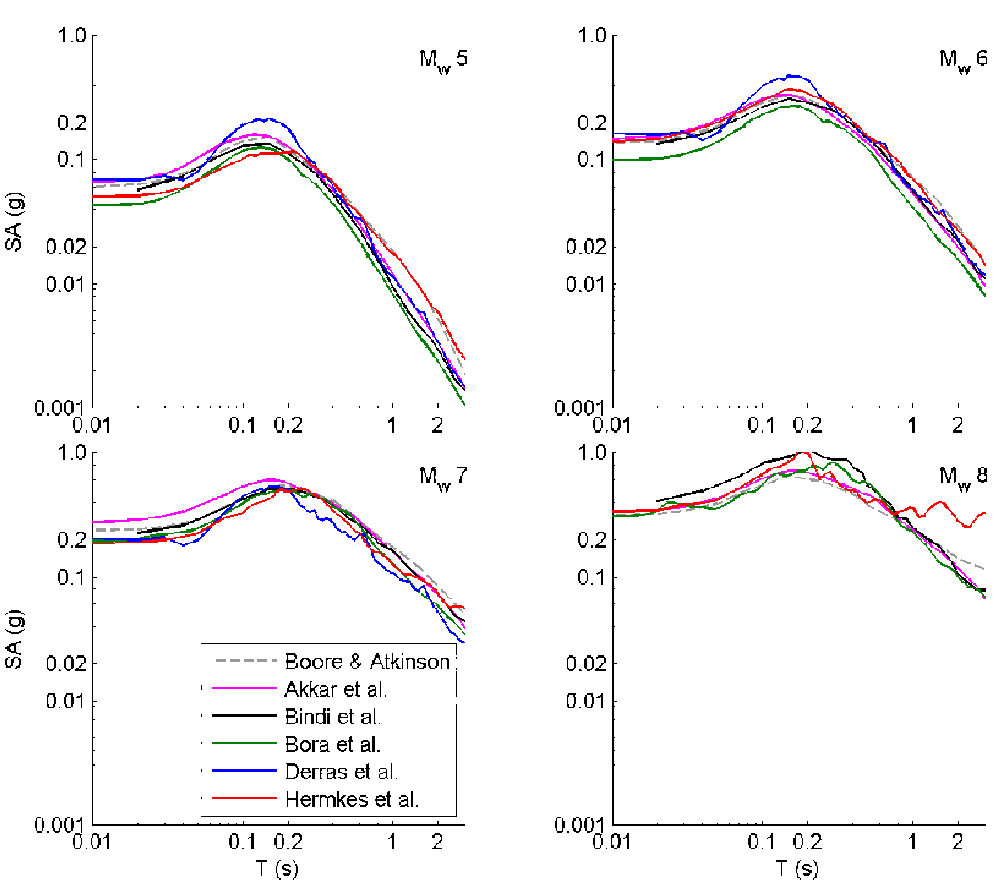

428 Figure 7: Comparison of median 5\% damped spectra for strike-slip earthquakes and $V_{S 30}=760 \mathrm{~m} / \mathrm{s}$ 429 (NEHRP B/C boundary) at $R_{J B}=10 \mathrm{~km}$ for $M_{w} 5$ (top left), 6 (top right), 7 (bottom left) and 8 (bottom 430 right). The predictions from the model of Derras et al. (2013) are not shown for $M_{w} 8$ since this is outside its range of applicability. The other models are shown for this magnitude even though some developers do not recommend their application for such large events. 

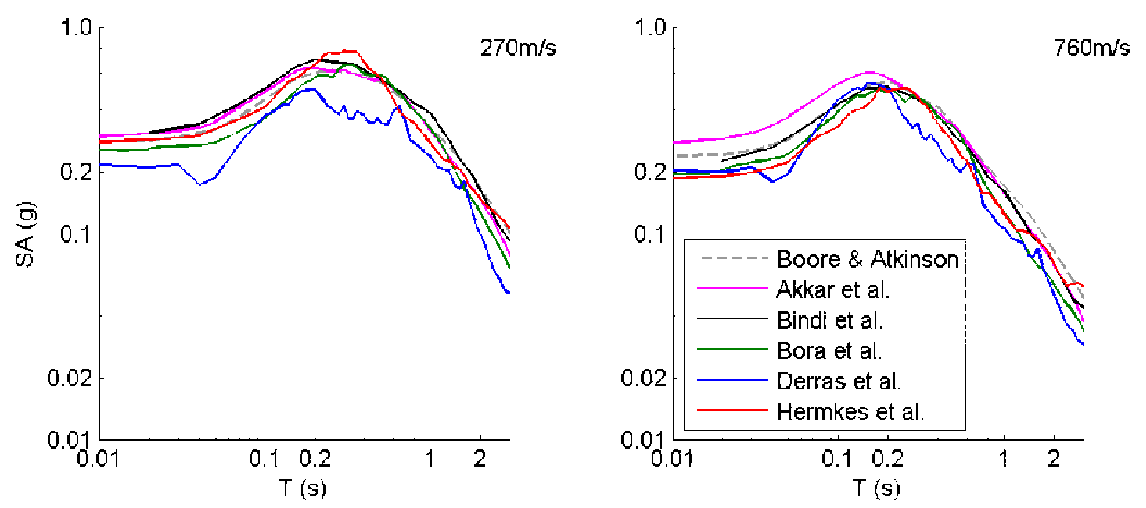

b)

435 Figure 8: Comparison of median 5\% damped spectra for strike-slip earthquakes at $R_{J B}=10 \mathrm{~km}$ for $M_{w} 7$ and a) $V_{S 30}=270 \mathrm{~m} / \mathrm{s}(\mathrm{NEHRP} D)$ and $\left.b\right) V_{S 30}=760 \mathrm{~m} / \mathrm{s}$ (NEHRP B/C boundary).
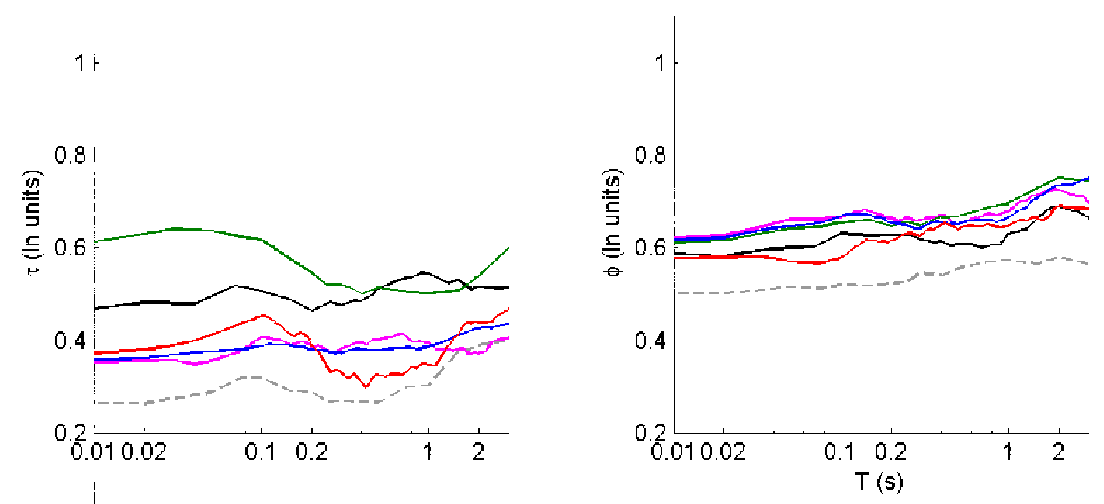

437

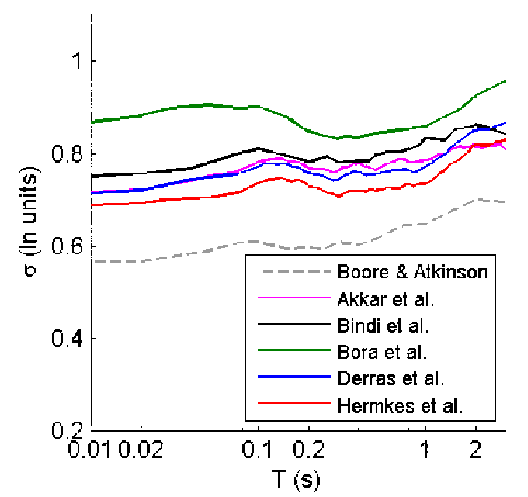

438 Figure 9: Comparison of the between-event (tau), within-event (phi) and total (sigma) standard deviations. All models have homoscedastic standard deviations. 
Table 1: Number of different earthquakes, stations and records used to derive the five models, magnitude and distance ranges of the data used, the ranges of applicability recommended by the model developers and the exclusion criteria used to select the records used to derive the model.

\begin{tabular}{|c|c|c|c|c|c|}
\hline Model & Akkar et al. & $\begin{array}{l}\text { Bindi et al. } \\
\left(\mathrm{V}_{\mathrm{S} 30} \text { model }\right)\end{array}$ & Bora et al. & Derras et al. & Hermkes et al. \\
\hline $\begin{array}{l}\text { Number of } \\
\text { earthquakes (E) }\end{array}$ & 221 & 225 & 369 & 320 & 279 \\
\hline $\begin{array}{l}\text { Number of stations } \\
\text { (S) }\end{array}$ & 322 & 345 & 341 & 201 & 251 \\
\hline $\begin{array}{l}\text { Number of records } \\
\text { (R) }\end{array}$ & 1041 & 1224 & 1232 & 1088 & 835 \\
\hline $\mathrm{R} / \mathrm{E}$ & 4.7 & 4.8 & 3.3 & 3.4 & 3.0 \\
\hline $\begin{array}{lrl}\mathrm{M}_{\min } \text { to } & \mathrm{M}_{\max } \\
\text { (data used) } & \end{array}$ & 4.0 to 7.6 & 4.0 to 7.6 & 4.0 to 7.6 & 3.6 to 7.6 & 4.0 to 7.6 \\
\hline $\begin{array}{l}M_{\min } \text { to } M_{\max } \\
\text { (recommended) }\end{array}$ & 4.0 to 8.0 & 4.0 to 7.6 & 4.0 to 7.6 & 4.0 to 7.0 & 4.0 to 7.6 \\
\hline $\begin{array}{l}\mathrm{R}_{\min } \text { to } \mathrm{R}_{\max }(\mathrm{km}) \\
\text { (data used) }\end{array}$ & 0 to 200 & 0 to 300 & 0 to 200 & 0 to $547 \mathrm{~km}$ & 0 to 200 \\
\hline $\begin{array}{l}\mathbf{R}_{\min } \text { to } \mathbf{R}_{\max }(\mathbf{k m}) \\
\text { (recommended) }\end{array}$ & 0 to 200 & 0 to 300 & 0 to 200 & 5 to $200 \mathrm{~km}$ & 0 to 200 \\
\hline $\begin{array}{l}\text { Record exclusion } \\
\text { criteria (other than } \\
\text { in terms of } \\
\text { magnitude and } \\
\text { distance) }\end{array}$ & $\begin{array}{r}\text { Singly-recorded } \\
\text { earthquakes; all } \\
\text { three components } \\
\text { not available; } \\
\text { focal depth } \\
\text { greater than } \\
30 \mathrm{~km} \text {; sites with } \\
\text { no measured } \\
\mathrm{V}_{\mathrm{S} 30} \text {; structural } \\
\text { period beyond } \\
\text { usable period } \\
\text { range defined by } \\
\text { Akkar and } \\
\text { Bommer (2006); } \\
\text { events with } \\
\mathrm{M}_{\mathrm{w}}<5 \text { with fewer } \\
\text { than } 3 \text { records; } \\
\text { unknown or } \\
\text { oblique style of } \\
\text { faulting; not free- } \\
\text { field. }\end{array}$ & $\begin{array}{r}\text { Unknown style } \\
\text { of faulting; sites } \\
\text { with no measured } \\
\text { VS30; singly- } \\
\text { recorded } \\
\text { earthquakes; only } \\
\text { records with low- } \\
\text { pass cut-off } \\
\text { frequency lower } \\
\text { than } 20 \mathrm{~Hz} \text { and } \\
\text { outside passband } \\
\text { of high-pass filter } \\
\text { all three } \\
\text { components not } \\
\text { available; focal } \\
\text { depth>35km. }\end{array}$ & $\begin{array}{r}\text { Not } \\
\text { representative of } \\
\text { shallow crustal } \\
\text { event; unknown } \\
\text { style of faulting; } \\
\text { only one } \\
\text { horizontal } \\
\text { component; sites } \\
\text { with no measured } \\
\mathrm{V}_{\mathrm{S} 30} \text {; poor quality } \\
\text { record; high-pass } \\
\text { cut-off frequency } \\
\text { higher than } \\
\text { Brune-source } \\
\text { corner frequency } \\
\text { for stress drop of } \\
100 \mathrm{bars} .\end{array}$ & $\begin{array}{r}\text { Focal depth more } \\
\text { than } 25 \mathrm{~km} \text {; sites } \\
\text { with no measured } \\
\mathrm{V}_{\mathrm{S} 30} \text {; unknown } \\
\text { style of faulting }\end{array}$ & $\begin{array}{r}\text { Unknown style of } \\
\text { faulting; sites } \\
\text { with no measured } \\
\mathrm{V}_{\mathrm{S} 30} \text {; not free- } \\
\text { field conditions; } \\
\text { high-pass cut-off } \\
\text { frequency higher } \\
\text { than } 0.25 \mathrm{~Hz}\end{array}$ \\
\hline
\end{tabular}

